\title{
The Evaluation of Characteristics of Turkish Z Generation Living Abroad Through Graphology
}

\section{Neriman KARA}

Graphologyst, Career and Communication Specialist

\begin{abstract}
The characteristics of $Z$ generation individuals constituting the majority of today's youth are quite different from those of previous generations' individuals. The individuals of this generation who spend their each and every moment on the internet and live their social life on this environment can shape their real life with this virtual life as well. While the fact that they can reach any information they want at any time enables them to be more brilliant on the one hand, this also prevents their emotional intelligence from improving. These individuals have some features like being rather self-confident, independent, introvert, dissatisfied, communicating only via social media, knowing what they want, expressing themselves quite well and desire to have all the control on their hand. Besides observations and empirical studies, it's also possible to evaluate the characteristics of the individuals and their lives by means of Graphology, whose validity and reliability have already been proved to be true and which has well-established in literature today. Graphology elicits the characteristics of the individual under the umbrella of the information based on his writing and signature. The aim of this study is to evaluate by means of Graphology whether the characteristics of Z generation living in Turkey and those of living in abroad are similar to each other or not. In this study, a group of 15 Turkish people living in England, who are $Z$ generation individuals, will be investigated with the help of Graphology. Thanks to this study, $Z$ generation individuals' features already available in the literature in Turkey will be compared with the findings that will be available at the end of our study.
\end{abstract}

Keywords: Z Generation, Graphology, Turkish Z Generation 